

\title{
Autogenous Shrinkage and Expansion Related to Compressive Strength and Concrete Composition
}

\author{
Elica Marušić ${ }^{1 *}$ and Nina Štirmer ${ }^{2}$
}

\begin{abstract}
An extensive research was undertaken in order to determine the dependence of shrinkage of high and normal strength concrete on the compressive strength and concrete composition. The part of research concerning dependence of autogenous shrinkage on compressive strength is presented in this paper.

Ten groups of concrete, with the total of twenty nine mixtures, were prepared. Concrete mixtures of each individual group were made using the same quantity of water, while the quantity of cement (CEM II/A-S 42,5R) and mineral admixture (silica fume) was varied in each group. Concrete groups differed according to the quantity of water.

Autogenous shrinkage of concrete was monitored together with the influence of initial curing in water on concrete shrinkage. Initial autogenous expansion was noticed during testing autogenous shrinkage, especially on normal strength concrete.

Based on the analysis of experimental results, the dependence of autogenous shrinkage at one day of concrete age on compressive strength was defined. The dependence of autogenous shrinkage at later ages on compressive strength of concrete was also presented.

Finally, the autogenous shrinkage components of best-known theoretical shrinkage prediction models were compared with experimental data.
\end{abstract}

\section{Introduction}

Designers specify the structural concrete strength class but also other mechanical, durability-related, and deformational properties of concrete, and so they also specify the greatest concrete shrinkage value for the structures for which this information is considered to be significant. In the second case, knowing mechanical properties that the concrete should meet, they wish to use them as the basis for estimating time-related deformations. Of course, it can not be expected that they will use micro-level or multi-level models that require specific knowledge. That is why macro-level engineering models have been developed. Concrete shrinkage is a time-related deformation and in each model the shrinkage value is given as related to time.

The concrete shrinkage is usually defined in relation to compressive strength in the macro-level engineering models that are currently most often used in practice. Shrinkage is not directly dependant on compressive strength, but rather indirectly, as both, the shrinkage and strength depend on concrete composition. As the concrete composition is usually unknown at the stage of concrete design, the compressive strength is recognised as the most suitable parameter for defining the dependence between shrinkage and concrete composition.

${ }^{1}$ Head of the Laboratory for Concrete, Institute IGH, Regional unit in Split, Split, Croatia.

*Corresponding author, E-mail: elica.marusic@igh.hr

${ }^{2}$ Professor, Faculty of Civil Engineering, University of Zagreb, Croatia.
Other generally known parameters that influence concrete shrinkage are ambient conditions (relative humidity in particular), geometry, and size of the element.

As ambient conditions are determined by the place in which concrete will be used, while dimensions of structural elements are determined by the design, the concrete composition is recognised as a feature that can be influenced at the stage of concrete design. Similarly, the shrinkage value may be assumed at the design stage according to the assumed concrete strength, based on the model showing dependence between the shrinkage and compressive strength.

In addition to concrete shrinkage due to drying, i.e. shrinkage caused by loss of moisture from concrete, recent models (EC2:2008 (EN 1992-1-1 (CEN 2004+2008)), CEB MC90-99 (fib 1999) and MC2010 (fib 2010)) also include the autogenous shrinkage component, i.e. the shrinkage that occurs as a consequence of chemical processes accompanying the hydration of cement. It is considered that the principle of superposition of autogenous shrinkage and drying shrinkage is applicable to the total concrete shrinkage. However, it has been demonstrated that the autogenous shrinkage in drying conditions is smaller than the autogenous shrinkage of sealed specimens (Yang et al. 2005; Ishida et al. 1998). This brings into question the principle of superposition of autogenous and drying shrinkage.

In addition, in practice it is very difficult to separate the measurement of drying shrinkage from the measurement of autogenous shrinkage. If marks are placed on the specimen in order to measure the change in length once specimen is extracted from the mould, then 
both shrinkage components are measured. Only the concrete shrinkage prior to extraction of concrete from the mould remains unmeasured.

Therefore, the objective is to obtain the total deformation of concrete, but without using the superposition principle for autogenous shrinkage and drying shrinkage, and to use instead the superposition principle for autogenous shrinkage at the age of one day, and the total shrinkage measured once the specimens are extracted from the mould.

In practical terms, shrinkage measurement after extraction of samples from the mould is a usual conventional test method that is also applied on samples prepared in laboratory, and on control samples taken during concrete placing.

Unlike conventional test method, the autogenous shrinkage measurement at the age of one day, i.e. before the samples are extracted from the mould, is a demanding testing for which a standard test method does not exist, and which in many instances can't even be conducted, especially when testing the concrete sampled during the placing process. It is therefore significant to have an idea about what is happening with samples before the start of conventional shrinkage measurement. The total shrinkage of concrete is then obtained by adding up the autogenous shrinkage at one day and conventionally measured shrinkage which includes autogenous shrinkage and drying shrinkage. That is why it is significant to define the concrete shrinkage model at one day of age.

Just like in the mentioned theoretical models, the autogenous shrinkage is presented as related to compressive strength because the compressive strength, as earlier mentioned, is the information about concrete that is known at the design stage, and it is also the parameter that represents the composition of concrete. This paper confirms once again that this dependence does exist, and an analytic expression is given for the dependence of autogenous deformations at the age of one day on the compressive strength. Unlike the above mentioned theoretical models, this paper graphically presents the dependence of autogenous deformations on compressive strength, and also on the concrete composition for a wide array of concrete compositions grouped according to quantity of water, which can assist designers in concrete composition design.

This overview of autogenous shrinkage also presents autogenous expansion as another aspect of early deformations. It is shown that autogenous shrinkage also exists in normal strength concretes, but it is compensated by previous autogenous expansion of concrete.

An attempt is also made in this paper to answer the question about the way in which initial cure influences autogenous shrinkage/expansion. Two parallel series of the same-composition concretes were prepared for that purpose. One of these series was subjected to autogenous deformation testing, while the influence of initial cure in water on concrete shrinkage was tested on the second series of samples. The results obtained point to the difference between the normal strength concrete and high strength concrete, and to the possibility that the initial autogenous expansion compensates the change in concrete volume during cure in water.

Finally, the autogenous shrinkage measurement results were compared with predictions given in the models that are most frequently used in practical applications.

\section{Description of investigations}

A series of 29 concrete mixtures was prepared. The mixtures were subjected to the testing of autogenous shrinkage and influence of initial concrete curing in water. The autogenous shrinkage was measured for a period of three to four months.

In this paper term "high strength concrete" is used for concrete with strength class $\mathrm{C} 50 / 60$ and higher as it is usual in practise (EN 206-1 (CEN 2000+2004+2005); (JCI 1998)). In recent version of EN 206 (CEN 2013) there is no definition of "high strength concrete" any more. Term "normal strength concrete" is used for concrete with strength class less then C 50/60. Term "normal to high strength concrete" is used for concrete groups where part of mixtures is normal strength and part high strength concrete.

\subsection{Concrete compositions}

The concrete with 29 compositions, classified in ten groups, was prepared. Each group consisted of two to three concrete mixtures of similar consistence, i.e. with approximately the same quantity of water. In each group, the quantity of cement, and hence the quantity of aggregate, was varied. Compositions of all prepared concrete mixtures are presented in Table $\mathbf{1 .}$

Fifteen concrete mix compositions were prepared according to the central cubic model with three factors (cement, water, silica fume), each at three levels as follows: cement $\left(360 \mathrm{~kg} / \mathrm{m}^{3}, 400 \mathrm{~kg} / \mathrm{m}^{3}, 440 \mathrm{~kg} / \mathrm{m}^{3}\right)$, water $\left(140 \mathrm{~kg} / \mathrm{m}^{3}, 160 \mathrm{~kg} / \mathrm{m}^{3}, 180 \mathrm{~kg} / \mathrm{m}^{3}\right)$, silica fume $(0$ $\left.\mathrm{kg} / \mathrm{m}^{3}, 15 \mathrm{~kg} / \mathrm{m}^{3}, 30 \mathrm{~kg} / \mathrm{m}^{3}\right)$. Four other mixtures were additionally prepared so as to cover all combinations of the full model, on three levels with two factors, cement and water. The superplasticiser and retarder were added to each of the above nineteen mixtures (groups D1, D2, D3, S1, S2, S3 and S4). Silica fume was added to concrete mixtures from groups S1, S2, S3 and S4.

An additional mixture with $480 \mathrm{~kg}$ of cement per $\mathrm{m}^{3}$ of concrete was also prepared in group S4.

In order to take into account the shrinkage of normal and normal to high strength concrete, additional nine concrete mixtures marked $\mathrm{O}$ were prepared. Out of these mixtures, six were made without chemical and mineral admixtures (groups $\mathrm{O} 1$ and $\mathrm{O} 2$ ), and three (group O3) were prepared with the two times smaller quantity of superplasticiser compared to the previously described twenty mixtures. 
Table 1 Concrete compositions (29 mixtures).

\begin{tabular}{|c|c|c|c|c|c|c|c|c|c|c|}
\hline $\begin{array}{l}\text { Group } \\
\text { mark }\end{array}$ & $\begin{array}{l}\text { Mixture } \\
\text { mark }\end{array}$ & $\begin{array}{c}\text { Water/ } \\
\text { cement ratio }\end{array}$ & $\begin{array}{c}\text { Water/ } \\
\text { binder ratio }\end{array}$ & $\begin{array}{l}\text { Cement } \\
(\mathrm{kg})\end{array}$ & $\begin{array}{l}\text { Water } \\
(\mathrm{kg})\end{array}$ & $\begin{array}{l}\text { Aggregate } \\
(\mathrm{kg})\end{array}$ & $\begin{array}{c}\text { Super- } \\
\text { plasticiser } \\
\text { (\% cem.) }\end{array}$ & $\begin{array}{l}\text { Retarder } \\
\text { (\% cem.) }\end{array}$ & $\begin{array}{l}\text { Silica } \\
\text { fume } \\
(\mathrm{kg})\end{array}$ & $\begin{array}{c}\text { Consistency } \\
\text { class }\end{array}$ \\
\hline \multirow{3}{*}{ D1 } & D1-360 & 0,389 & 0,389 & 360 & 140 & 1963 & 1,5 & 0,2 & - & \multirow{3}{*}{$\mathrm{S} 2 / \mathrm{F} 2$} \\
\hline & D1-400 & 0,350 & 0,350 & 400 & 140 & 1908 & 1,5 & 0,2 & - & \\
\hline & D1-440 & 0,318 & 0,318 & 440 & 140 & 1885 & 1,5 & 0,2 & - & \\
\hline \multirow{3}{*}{ D2 } & D2-360 & 0,444 & 0,444 & 360 & 160 & 1923 & 1,5 & 0,2 & - & \multirow{3}{*}{$\mathrm{S} 4 /(\mathrm{F} 4 / \mathrm{F} 5)$} \\
\hline & D2-400 & 0,400 & 0,400 & 400 & 160 & 1884 & 1,5 & 0,2 & - & \\
\hline & D2-440 & 0,364 & 0,364 & 440 & 160 & 1847 & 1,5 & 0,2 & - & \\
\hline \multirow{3}{*}{ D3 } & D3-360 & 0,500 & 0,500 & 360 & 180 & 1877 & 1,5 & 0,2 & - & \multirow{3}{*}{ F6 } \\
\hline & D3-400 & 0,450 & 0,450 & 400 & 180 & 1838 & 1,5 & 0,2 & - & \\
\hline & D3-440 & 0,409 & 0,409 & 440 & 180 & 1798 & 1,5 & 0,2 & - & \\
\hline \multirow{3}{*}{ S1 } & $\mathrm{S} 1-360$ & 0,500 & 0,462 & 360 & 180 & 1838 & 1,5 & 0,2 & 30 & \multirow{3}{*}{ F6 } \\
\hline & $\mathrm{S} 1-400$ & 0,450 & 0,434 & 400 & 180 & 1814 & 1,5 & 0,2 & 15 & \\
\hline & $\mathrm{S} 1-440$ & 0,409 & 0,383 & 440 & 180 & 1759 & 1,5 & 0,2 & 30 & \\
\hline \multirow{3}{*}{$\mathbf{S 2}$} & $\mathrm{S} 2-360$ & 0,444 & 0,427 & 360 & 160 & 1902 & 1,5 & 0,2 & 15 & \multirow{3}{*}{$\mathrm{S} 5 /(\mathrm{F} 4 / \mathrm{F} 5)$} \\
\hline & S2-400 & 0,400 & 0,386 & 400 & 160 & 1860 & 1,5 & 0,2 & 15 & \\
\hline & S2-440 & 0,364 & 0,352 & 440 & 160 & 1826 & 1,5 & 0,2 & 15 & \\
\hline \multirow{3}{*}{ S3 } & S3-360 & 0,389 & 0,359 & 360 & 140 & 1919 & 1,5 & 0,2 & 30 & \multirow{3}{*}{$\mathrm{S} 1 / \mathrm{F} 1$} \\
\hline & S3-400 & 0,350 & 0,337 & 400 & 140 & 1879 & 1,5 & 0,2 & 15 & \\
\hline & S3-440 & 0,318 & 0,298 & 440 & 140 & 1843 & 1,5 & 0,2 & 30 & \\
\hline \multirow{2}{*}{ S4 } & $\mathrm{S} 4-400$ & 0,400 & 0,372 & 400 & 160 & 1844 & 1,5 & 0,2 & 30 & \multirow{2}{*}{$\mathrm{S} 4 / \mathrm{F} 3$} \\
\hline & S4-480 & 0,340 & 0,320 & 480 & 163 & 1763 & 1,5 & 0,2 & 30 & \\
\hline \multirow{3}{*}{ O1 } & O1-320 & 0,625 & 0,625 & 320 & 200 & 1865 & - & - & - & \multirow{3}{*}{$\mathrm{S} 3 /(\mathrm{F} 3 / \mathrm{F} 4)$} \\
\hline & O1-360 & 0,556 & 0,556 & 360 & 200 & 1825 & - & - & - & \\
\hline & O1-400 & 0,500 & 0,500 & 400 & 200 & 1790 & - & - & - & \\
\hline \multirow{3}{*}{$\mathbf{O 2}$} & $\mathrm{O} 2-360$ & 0,603 & 0,603 & 360 & 217 & 1784 & - & - & - & \multirow{3}{*}{$\mathrm{S} 4 / \mathrm{F} 5$} \\
\hline & $\mathrm{O} 2-400$ & 0,550 & 0,550 & 400 & 220 & 1741 & - & - & - & \\
\hline & $\mathrm{O} 2-440$ & 0,507 & 0,507 & 440 & 223 & 1699 & - & - & - & \\
\hline \multirow{3}{*}{$\mathbf{O 3}$} & O3-360 & 0,547 & 0,547 & 360 & 197 & 1832 & 0,8 & 0,2 & - & \multirow{3}{*}{ F6 } \\
\hline & O3-400 & 0,500 & 0,500 & 400 & 200 & 1789 & 0,8 & 0,2 & - & \\
\hline & O3-440 & 0,461 & 0,461 & 440 & 203 & 1744 & 0,8 & 0,2 & - & \\
\hline
\end{tabular}

\subsection{Concrete components}

The cement type CEM II/A-S 42,5R, calcareous aggregate and water from municipal water supply system were used for the preparation of all mixtures.

The fraction content was as follows: $0 / 4 \mathrm{~mm}(55 \%)$, $4 / 8 \mathrm{~mm}(10 \%), 8 / 16 \mathrm{~mm}(35 \%)$. Quantities of water and aggregate given in Table 1 are related to the saturated-surface-dry aggregate.

The superplasticiser based on the polycarboxylate ether polymer (PCE) was used in groups $\mathrm{D}, \mathrm{S}$ and $\mathrm{O} 3$.

The quantity of retarder added to all mixtures, except for six mixtures belonging to concrete groups $\mathrm{O} 1$ and $\mathrm{O} 2$, amounted to 0,2 percent of cement weight.

The silica fume consisting of $(85-98)$ percent of microscopic spherical particles of amorphous silicon dioxide $\left(\mathrm{SiO}_{2}\right)$, with an average grain size diameter ranging from $0,10 \mu \mathrm{m}$ to $0,15 \mu \mathrm{m}$ was used.

\subsection{Description of testing}

The consistency of fresh concrete was tested by slump test according to EN 12350-2 (CEN 2009) and by flow table test according to EN 12350-5 (CEN 2009). The consistency class is presented in Table 1.

The compressive strength was tested on $15 \mathrm{~cm}$ cubes, and on cylinders $15 \mathrm{~cm}$ in diameter and $30 \mathrm{~cm}$ in height, all in accordance with EN 12390-3 (CEN 2009+2011).

\subsubsection{Shrinkage - conventional testing proce- dure}

In order to explore influence of initial water curing on autogenous shrinkage, conventional testing procedure and water curing method were performed on specimens parallel to those prepared for autogenous shrinkage measurement. Specimens were taken from same concrete mixture.

The shrinkage was tested on $(10 \times 10 \times 40) \mathrm{cm}$ prisms After the concrete was placed into moulds, the specimens were covered with foil to prevent loss of moisture and left in the room at the temperature $(20 \pm 2){ }^{\circ} \mathrm{C}$ and at relative humidity of $>70 \%$. After 24 hours, the specimens were extracted from the moulds and bench marks were glued onto them at the distance of $150 \mathrm{~mm}$ along the centre of the central line on two opposite lateral sides of the specimen. This procedure was conducted within 10 minutes following specimen extraction from the mould. First measurement was taken.

After that specimens were placed in water at the temperature of $(20 \pm 2){ }^{\circ} \mathrm{C}$ for the next 48 hours. After extraction from water, the surface of the specimens was wiped, their mass was measured, and the second measurement was taken (repeated at each face two more times alternately). These actions were conducted within two minutes following extraction of specimens from the water. 
The shrinkage measurements were made using the length comparator with a digital dial gauge accurate to $0,001 \mathrm{~mm}$.

Test results of volume and mass change are presented in item 6.

\subsubsection{Autogenous shrinkage - testing proce- dure}

According to RILEM recommendations (RILEM 1998), the autogenous shrinkage measurement starts immediately after removal of mould and specimen sealing, at one day of age. According to the German standard DIN 1045-1 (DIN 2008), the autogenous shrinkage measurement also starts at the concrete age of one day but, in this way, a considerable part of deformation caused by autogenous shrinkage of high strength concrete remains unmeasured (Aïtcin 1998).

The measurement method described in the doctoral thesis by Drago Saje (2001) is used as the basis for autogenous shrinkage measurements presented in this paper because it is linear measurement method of horizontal shrinkage (Holt and Leivo 1998) in standard moulds for conventional shrinkage testing procedure, so that the incompatibility between results of measurement of autogenous and total shrinkage due to specimen shape could be avoided. The method was improved in the way of enabling free movement of concrete in the mould and settlement of measuring arrangement.

Moulds made of polyethylene foil $0,5 \mathrm{~mm}$ in thickness were fabricated for the placement of concrete specimens to be used for autogenous shrinkage measurements. Two shorter lateral sides of the mould are square plates made of stainless steel $97 \mathrm{~mm}$ in length, and $0,8 \mathrm{~mm}$ in thickness. From the inside, the plates are roughened so as to ensure the best possible connection with the concrete. The plate centre was marked from the outside. The connection between the plate and polyethylene foil was realized by means of a strong watertight adhesive strip $5 \mathrm{~cm}$ in width. A narrow polyethylene strip about $5 \mathrm{~mm}$ in width was glued at the connection with the foil so as to prevent full connection of the plate and the adhesive strip. This has enabled free movement

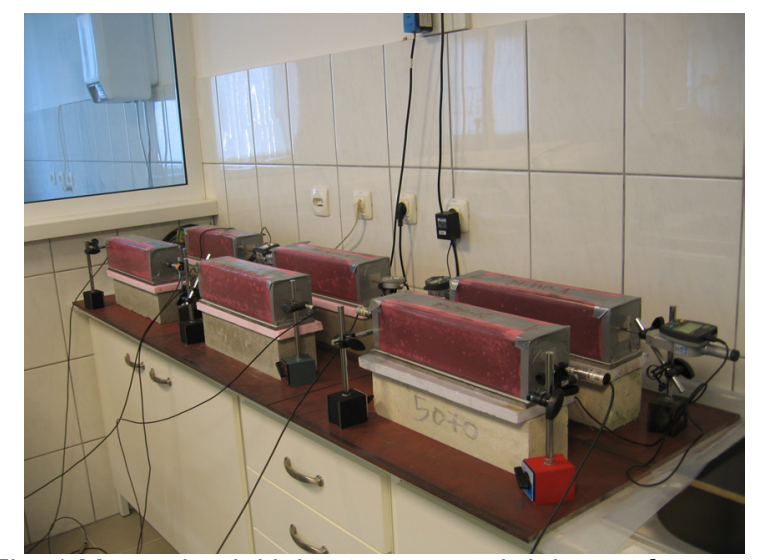

Fig. 1 Measuring initial autogenous shrinkage of concrete specimens. of the plate in the mould once the mould is closed, without any leakage of concrete.

After fabrication, plastic moulds with plates were placed within standard metal $(10 \times 10 \times 40) \mathrm{cm}$ moulds, on to a Teflon coat $1 \mathrm{~mm}$ in thickness. After concrete placement, the top of the mould made of polyethylene foil was closed and sealed with a watertight strip.

The concrete temperature was monitored with a temperature probe, as the initial increase in temperature points to the start of the setting process. It is considered that the shrinkage does not occur before the start of the setting, i.e. the deformation that occurs when the cement paste is still in the fresh state and when there are no stresses that occur in the paste during hardening is not taken into account (JCI 1998). At the onset of the setting process, the strength of the cement aggregate skeleton is sufficient enough for the concrete to maintain its shape. This is the moment in which specimens for measuring autogenous shrinkage were freed from metal sides of the mould. Before measurement, the metal base was placed on the support made of material that does not transfer heat. The inductive displacement sensors were placed horizontally from each side into the centre of the metal plate (Fig. 1). The measurement data were collected using an appropriate data collection system.

The inductive displacement sensors were removed from specimens at the concrete age of 24 to 36 hours. Holes were cut in moulds and bench marks were glued onto concrete. After that the autogenous shrinkage was measured in a traditional way, using the length comparator accurate to $0,001 \mathrm{~mm}$. Specimens were kept in a room at a relative humidity of more than $70 \%$. The specimen mass was measured at each autogenous shrinkage measurement.

Mass measurements have shown that the quality of specimen sealing in the plastic mould is good, as the specimens of approximately $10 \mathrm{~kg}$ lost less than $1 \mathrm{~g}$ in the period of ninety days.

One of the main problems in testing autogenous shrinkage is how to avoid friction between mould and concrete and to enable unrestrained movement of concrete inside the mould (Hammer 1998). Before start of experiment there was period of adjusting the testing procedure. By comparing results obtained from five pairs of inductive transducers placed on surface of stainless steel plates it was concluded that movement of whole sample is uniform and can be represented by measuring the movement of the central point. The surfaces of plastic mould were very smooth in order to enable unrestrained movement of sample in mould. That was confirmed by performing parallel testing with slightly greased plastic mould surfaces.

\section{Test results for autogenous shrinkage}

Eight groups of concrete, out of ten groups in total, contained a retarder, which made it possible to harmonize the initial temperature of concrete with the ambient 
temperature before the start of the setting process. The time when the concrete temperature starts to increase was adopted as the start of setting process.

The intensive hydration process caused an increase in concrete temperature. The autogenous shrinkage value was corrected to take into account the thermal expansion of concrete.
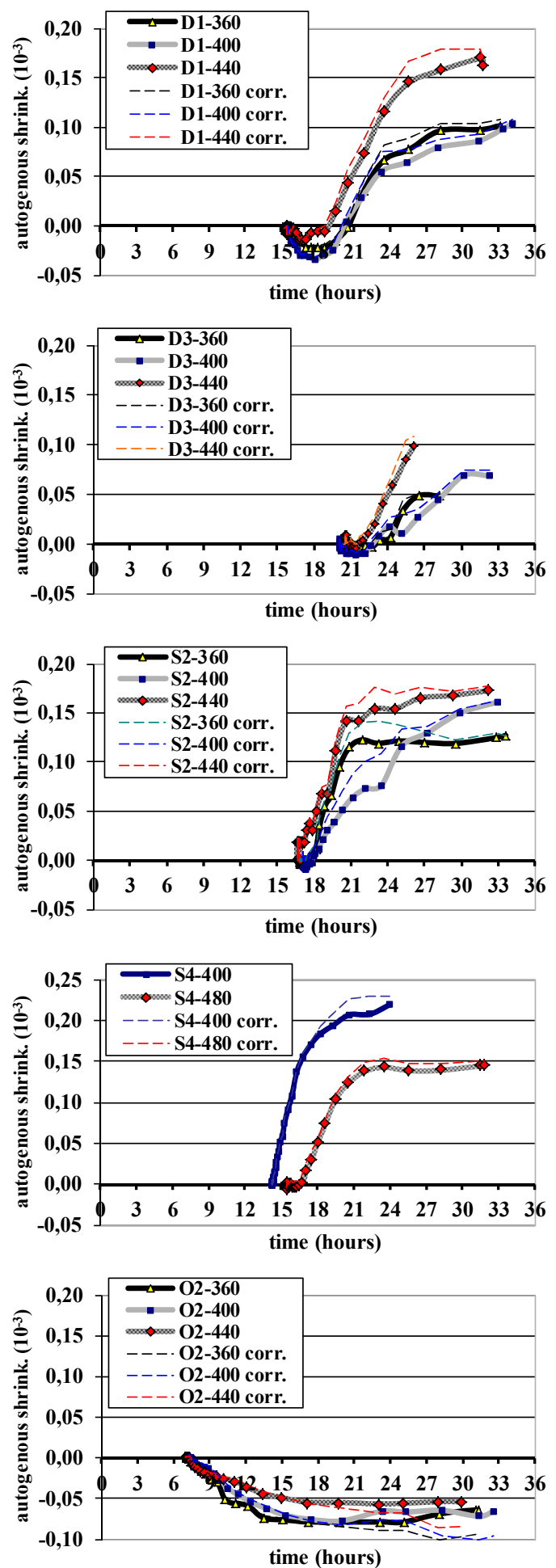

3.1 Test results for initial autogenous shrinkage

Figure 2 shows initial autogenous shrinkage results obtained by means of inductive displacement sensors until the concrete age of a little more than one day, with the correction of results to take into account deformation due to temperature changes occurring during the cement hydration process. Each graph shows autoge-
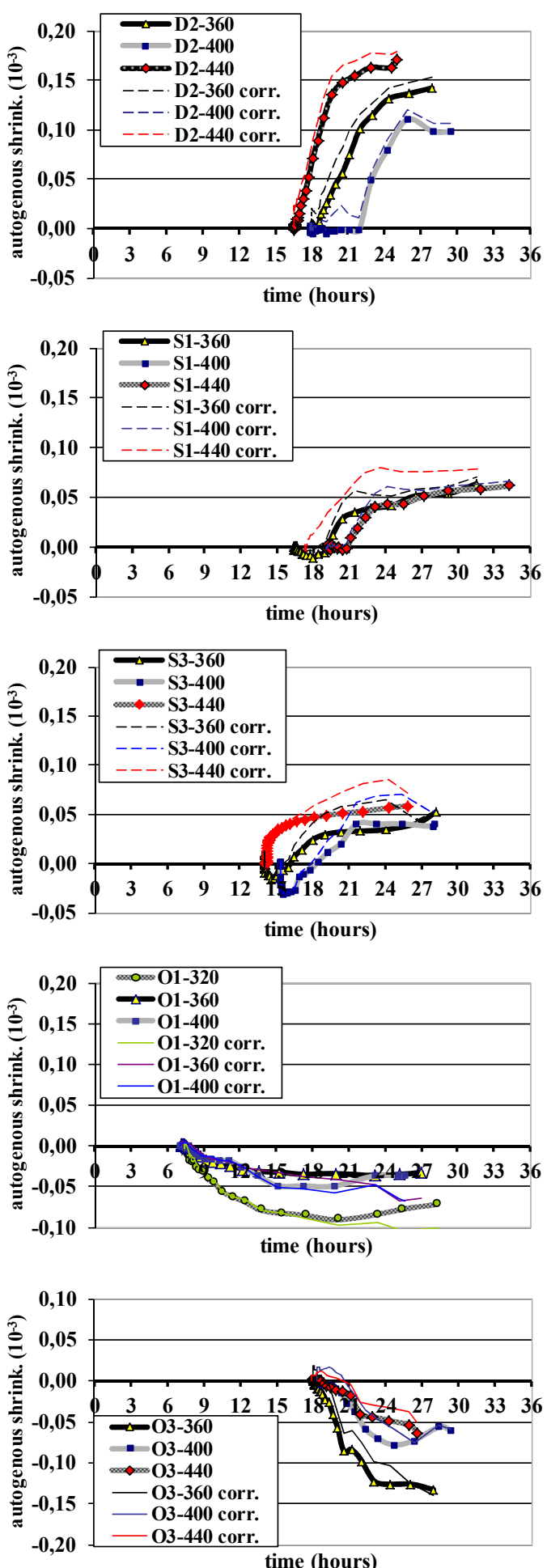

Fig. 2 Autogenous shrinkage of concrete from the start of setting to the age of more than one day, measured using inductive displacement sensors with correction for thermal expansion. 
nous shrinkage test results for one group of concrete mixtures.

The intensive hydration process caused an increase in concrete temperature. The autogenous shrinkage value was corrected to take into account the thermal expansion of concrete. The coefficient of thermal expansion of fresh concrete was determined based on literature data and, in this respect, the value of $1,48 \times 10^{-5}{ }^{\circ} \mathrm{C}^{-1}$ according to measurement provided by D. Saje (2001) was adopted. This value linearly changes until 1,20 $\mathrm{x}$ $10^{-5}{ }^{\circ} \mathrm{C}^{-1}$ at the age of one day according to E. Holt (2001) and then, at the age of about two days, i.e. when the specimen temperature becomes once again equal to the ambient temperature, the already known thermal expansion coefficient for hardened concrete, i.e. 1,00 x $10^{-5}{ }^{\circ} \mathrm{C}^{-1}$, is adopted (EN 1991-1-5 (CEN 2003); Mehta 2006).

A significant autogenous expansion can be noticed on the last three graphs where autogenous shrinkage results for normal and normal to high strength concrete are presented.

\subsubsection{Autogenous expansion of concrete}

At the beginning of the setting process, i.e. at the start of the autogenous shrinkage measurements, a negative shrinkage, or expansion of concrete was registered at some concrete compositions. This phenomenon has already been noted by some researchers (Hammer 1998; Tazawa and Miyazawa 1995), while in most literature the autogenous expansion is not mentioned at all, probably because it does not occur at all times, or because the autogenous shrinkage of normal strength concrete is rarely tested. Possible causes of this occurrence are:

- use of retarders (Paulini 1990) - a greater quantity of retarder causes greater initial expansion,

- a greater quantity of $\mathrm{C}_{2} \mathrm{~S}$ (belite) that causes an increase in volume (JCI 1998),

- bleed water re-absorption that happens in the period immediately prior to and at the start of the setting process (Hammer 1998; Holt 2001).
The bleed water accumulates on the surface due to settlement that occurs after preparing of concrete. When the settlement ends and there is no drying, the concrete reabsorbs the bleed water, which is of assistance during hydration of cement. The re-absorption of water causes expansion of concrete. This phenomenon occurs in concrete mixtures with excess water and, depending on the quantity, it can last until the end of the setting process. This phenomenon does not occur in stiff mixtures. This re-absorption of water is confirmed by a slight increase in capillary pressure (Holt 2001).

Expansion in the time around start of setting process isn't noticed only in high $w / c$ samples, as it can be seen in Fig. 2, but its value in high $w / c$ samples is significant and at age of one day isn't still compensated by autogenous shrinkage.

It is generally known that in concrete mixes with $w / c$ greater then 0,42 there is enough water for fully hydration of cement (Jensen and Hansen 2001). That means that reabsorbed water can serve as internal water source in capillary pores for hydration process and, in that way, decreases or eliminates self-desiccation. Measured autogenous shrinkage, as external phenomenon of chemical shrinkage, indicates the continuation of hydration process (Tazawa et al. 2000). Because of greater quantity of reabsorbed water in concrete with greater $w / c$, autogenous shrinkage values are significantly lower (Figs. 3 and 4).

The initial expansion of concrete is highly pronounced in concrete of normal and normal to high strength, i.e. in concrete with the compressive strength of up to $60 \mathrm{MPa}$ (nine mixtures in groups $\mathrm{O} 1, \mathrm{O} 2$, and $\mathrm{O} 3)$. All three concrete groups $(\mathrm{O} 1, \mathrm{O} 2$ and $\mathrm{O} 3)$ are characterized by the quantity of water that is greater when compared to other mixtures, although only two out of the three groups have a liquid consistency. It is not the question of excess water in case of group O1, as concrete mixtures belonging to this group have the quantity of water that is needed to achieve the slump consistency of $90 \mathrm{~mm}$. The retarder was added to mix-

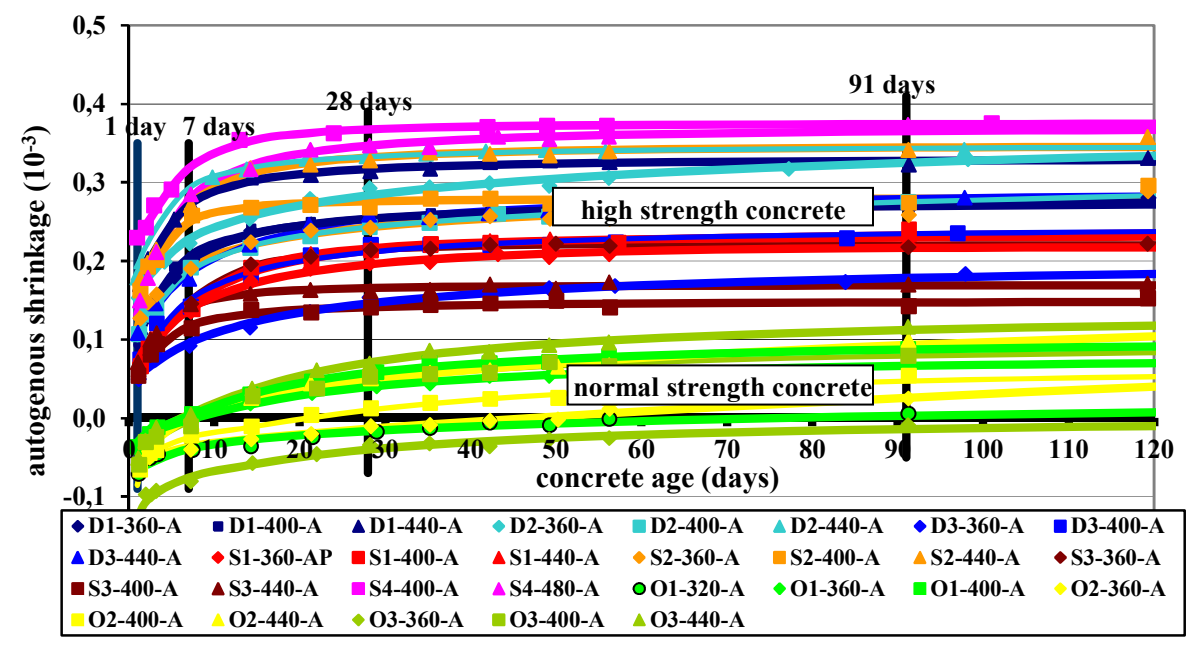

Fig. 3 Autogenous shrinkage test results (measured values rather than corrected values are given for groups 01 and $\mathrm{O} 2)$. 
tures belonging to only one concrete group (O3), while the retarder was not added to the other two groups $(\mathrm{O} 1$ and $\mathrm{O} 2$ ). That is why it is more probable that the initial expansion of concrete is due to higher water content rather than to the addition of retarder.

The autogenous expansion of high strength concrete mixtures from groups D1 and S3, with 1401 of water per $\mathrm{m}^{3}$, is much less significant. It is even less notable in concrete belonging to groups S1 and D3 with 1801 of water, while no expansion was noted for concrete from groups D2, S2, and S4 which have 1601 of water per $\mathrm{m}^{3}$ of concrete.

The initial autogenous expansion of concrete may be due to a greater quantity of belite $\left(\mathrm{C}_{2} \mathrm{~S}\right)$ in cement, which swells and hence reduces autogenous shrinkage (Tazawa and Miyazawa 1995). However, as all mixtures were made with the same type of cement, the initial autogenous expansion of concrete is most probably due to the quantity of water as it was presented above.

\subsection{Test results for autogenous shrinkage until 90 (120) days after preparation of concrete}

Test results for autogenous shrinkage of all groups of concrete in the period until 120 days are presented in Fig. 3 together with approximate time curves.

The concrete with a larger quantity of water, i.e. the concrete of normal and normal to high strength is characterized by an increase in volume immediately after the start of the setting process, which lowers the value of the change in length that occurs in the time after the first day following production of concrete.

It is possible that low initial shrinkage of normal strength concrete is in fact due to the expansion of concrete at the beginning of the setting process.

\section{Dependence of autogenous shrinkage on compressive strength}

The dependence of autogenous shrinkage on compressive strength changes over time. That is why it is monitored in different time frames that are represented with vertical lines in Fig. 3. The dependence of autogenous shrinkage on compressive strength in appropriate time intervals is presented in Fig. 4.

\subsection{Analysis of test results - autogenous shrinkage of concrete}

For one concrete group with the same quantity of water, the compressive strength increases with an increase in the quantity of cement (straight lines in Fig. 4), the water/cement ratio decreases and the autogenous shrinkage increases at the concrete age of one day.

The initial dependence of autogenous shrinkage on compressive strength changes with the age of concrete and this in such a way that the straight line in the compressive strength range from $70 \mathrm{MPa}$ to $90 \mathrm{MPa}$ bends in a clockwise direction, which is mostly due to autogenous shrinkage of concrete containing silica fume. The increase of autogenous shrinkage reduces with an increase in compressive strength.
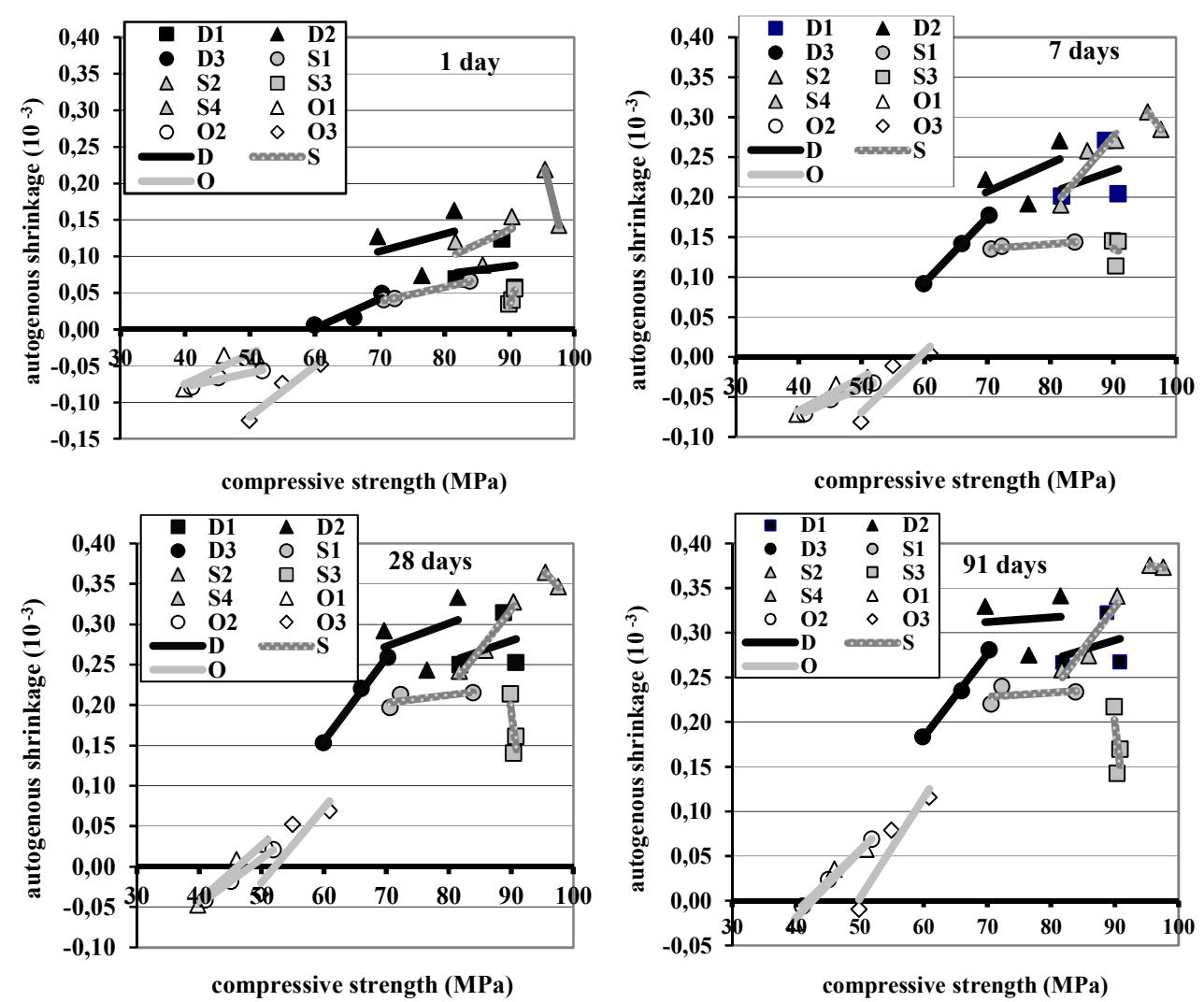

Fig. 4 Relationship between autogenous shrinkage and compressive strength of concrete for four concrete age intervals. 
Although in the compressive strength range of more than $70 \mathrm{MPa}$, or water/cement ratio of less than 0,45 , the shrinkage of concrete in one group with the same quantity of water can be well approximated with a straight line, the concrete shrinkage of different groups exhibits great dispersion, depending on the quantity of water and the silica fume content. For one value of compressive strength or one value of water/cement ratio, the autogenous shrinkage in this area has a great range of up to $0,25 \times 10^{-3}$.

It is important to note that the autogenous shrinkage of normal strength concrete (up to $60 \mathrm{MPa}$ ) fully coincides with the high strength concrete behaviour pattern. In case of normal strength concrete groups, the negative autogenous shrinkage or autogenous expansion was measured at one day of age, and this phenomenon was so pronounced that the subsequent autogenous shrinkage was able to eliminate it only at 14 to 91 days of age, depending on the group and compressive strength of concrete (Fig. 3). Expansion registered in low water/cement mixtures was compensated with autogenous shrinkage in very short time of few hours (Fig. 2).

A similar example was observed in literature (Hanehara et al. 1998) on a cement paste with the water/cement ratio of 0,5 , where the autogenous shrinkage did not attain the initial autogenous expansion value even after more than six days, while the initial autogenous expansion value was obtained within several hours for the autogenous shrinkage of cement paste with the water/cement ratio of 0,25 .

The cause should be sought in the quantity of water in concrete mixtures from groups $\mathrm{O} 1, \mathrm{O} 2$ and $\mathrm{O} 3$ that was greater than in case of the group D3, where the autogenous shrinkage is negligible during the first day (Figs. 4 and 5).

Thus the autogenous shrinkage also occurs in case of normal strength concrete, but it is much less pronounced than the autogenous shrinkage of the high strength concrete. The greater the quantity of water in high strength concrete, the smaller the initial increase in autogenous shrinkage. For the concrete with less than 1801 of water

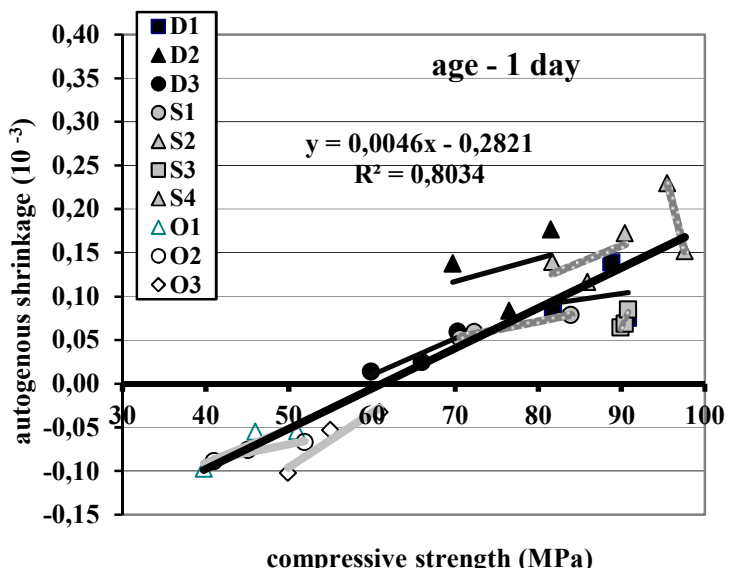

Fig. 5 Linear approximation of autogenous shrinkage at one day of age. per cubic meter, the increase of autogenous shrinkage in the first day amounted to 34 to 48 percent, and at seven days from 72 to 82 percent, of the autogenous shrinkage after 91 days. At the same time, the autogenous shrinkage of normal strength concrete had an increase of 26 to 46 percent at seven days with respect to the autogenous shrinkage value after 91 days, with the zero point at the concrete age of one day.

\subsection{Autogenous shrinkage of concrete at one day of age}

It is important to define the autogenous shrinkage at one day of age, as this is the shrinkage that gives, together with the shrinkage measured in a conventional way, the total shrinkage of concrete.

The straight line approximation of autogenous shrinkage (Fig. 5) represents the total deformation of concrete due to shrinkage at one day of age, and it amounts to:

$$
\varepsilon_{\text {ska1 }}=0,0046 f_{c m 28}-0,2821
$$

$\varepsilon_{\text {skal }}$ is autogenous shrinkage of concrete at one day of age $\left(10^{-3}\right.$ or $\left.\mathrm{mm} / \mathrm{m}\right)$

$f_{c m 28}$ is mean compressive strength of concrete at 28 days tested on a $15 \mathrm{~cm}$ cube (MPa)

The coefficient of determination $\left(\mathrm{R}^{2}\right)$ amounts to 0,803 .

According to this model, the autogenous shrinkage occurs in concrete one day after concrete production at the concrete compressive strength of $61,3 \mathrm{MPa}$ or more. A negative autogenous shrinkage or autogenous expansion is registered in case of lower-strength concretes.

\subsection{Correction of negative autogenous shrink- age}

Regarding the issue of whether or not to include the negative autogenous shrinkage in the shrinkage model, and which is the reference point for the start of the shrinkage measurement, E. Holt describes in her paper (Holt 2001) three possible reference points, depending on the approach to the problem:

(1) The scientific approach to autogenous shrinkage where the reference point for the autogenous shrinkage measurement is at the very beginning of the change in concrete volume.

(2) The engineering approach to autogenous shrinkage where conclusions should not depend on the testing arrangement. The start of shrinkage measurement is after the bleed water re-absorption which caused the concrete expansion. If there is no bleeding, the reference point is the start of the setting process. The autogenous shrinkage should be corrected for the deformation caused by the change in temperature.

(3) The structural approach to autogenous shrinkage the interpretation of data depends on the testing arrangement. The autogenous shrinkage is not cor- 


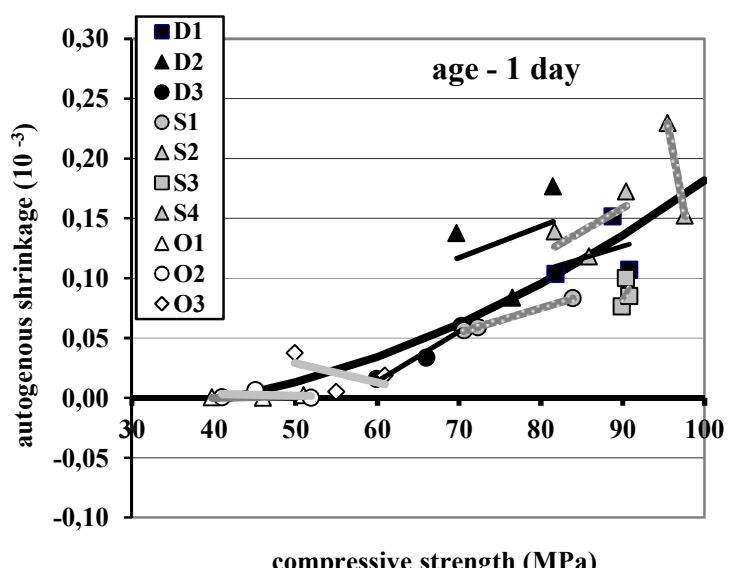

Fig. 6 Autogenous shrinkage of concrete corrected for deformation due to change in temperature and negative shrinkage, approximated by parabola.

rected for the deformation due to the change in temperature. The reference point for the start of testing is the moment of maximum temperature, i.e. the point in which thermal expansion has stopped.

In this paper, the autogenous shrinkage test results are given according to the engineering and structural approaches, but the engineering approach was adopted for the analysis of autogenous shrinkage.

The autogenous shrinkage of concrete at the age of one day corrected for deformation due to change in temperature and negative shrinkage, presented in Fig. 6, is approximated with parabola using the equation:

$$
\varepsilon_{\text {skalk }}=0,0000312 \cdot f_{c m 28}^{2}-0,0013 \cdot f_{c m 28}
$$

$\varepsilon_{\text {skalk }}$ is autogenous shrinkage at one day of age corrected for deformation due to change in temperature and negative shrinkage $\left(10^{-3}\right.$ or $\left.\mathrm{mm} / \mathrm{m}\right)$

The equation has a zero at the point of 41,7 MPa. For the concrete with the compressive strength of less than 41,7 MPa, the autogenous shrinkage at one day of age will be equal to zero.

\section{Comparison of models and experimental test results}

Theoretical models (EC2:2008 (EN 1992-1-1 (CEN
2004+2008)), CEB MC90-99 (FIB 1999) and MC2010 (FIB 2010)) that include the autogenous shrinkage component were compared with experimental data using the correlation method and statistical indicators.

\subsection{Correlation between autogenous shrinkage of concrete and autogenous shrinkage calcu- lated according to models}

The correlation between experimental data and data obtained by modelling is presented in graphs shown in Fig. 7. It is obvious that the autogenous shrinkage of concrete, the high strength concrete in particular, is significantly underestimated by models EC2:2008, CEB MC90-99 and MC2010. The correlation between experimental data at one day of age and data obtained by approximation curve described in item 4.3 is presented in graph shown in Fig. 7, too.

\subsection{Evaluation of models according to statisti- cal indicators}

The comparison of models with experimental data was also made through determination of CEB statistical indicators and $\mathrm{BP}$ variation coefficients described in ACI 209R-08 (ACI 2008),

The Table 2 provides values of CEB statistical indicators: variation coefficient $V_{C E B}$, mean square error $F_{C E B}$, and mean deviation $M_{C E B}$, as well as values of partial indicators in the intervals from 0 to 10 days and from 11 to 100 days. The $B P$ variation coefficient value is also presented.

Variation coefficient values for the three theoretical models are approximately the same, because they have the same theoretical basis.

Coefficient of variation indicates dissipation of results or model's precision. Mean square error uses the difference between the calculated and observed values relative to the observed value while mean deviation indicates systematic overestimation or underestimation of a given model.

Statistical indicators presented in Table $\mathbf{2}$ are given for autogenous shrinkage component of presented models. The values of statistical indicators when models are applied on all results points to significant overestimation of values of autogenous shrinkage due to significant overestimation of shrinkage in first 10 days. In the period of 11 to 100 days shrinkage is underestimated.

Table 2 Statistical indicators for autogenous shrinkage prediction models applied on experimental set of data.

\begin{tabular}{|c|c|c|c|c|c|c|c|c|c|c|}
\hline \multirow{3}{*}{ MODEL } & \multirow{2}{*}{\multicolumn{3}{|c|}{ CEB statistical indicators }} & \multicolumn{6}{|c|}{ Time } & \multirow{3}{*}{$\begin{array}{c}\text { BP variation coefficient } \\
\qquad \omega_{B P}\end{array}$} \\
\hline & & & & \multicolumn{3}{|c|}{ 1-10 days } & \multicolumn{3}{|c|}{ 11-100 days } & \\
\hline & $V_{C E B}$ & $F_{C E B}(\%)$ & $M_{C E B}$ & $V_{i}$ & $F_{i}(\%)$ & $M_{i}$ & $V_{i}$ & $F_{i}(\%)$ & $M_{i}$ & \\
\hline \multicolumn{11}{|c|}{ Models applied on experimental set of data } \\
\hline EC2:2008 & 0,894 & 1092,2 & 1,6 & 1,058 & 1543,5 & 2,8 & 0,693 & 60,6 & 0,4 & 0,76 \\
\hline CEB MC90-99 & 0,841 & 1379,3 & 2,0 & 1,003 & 1949,9 & 3,5 & 0,640 & 54,0 & 0,5 & 0,65 \\
\hline MC2010 & 0,895 & 1181,3 & 1,7 & 1,054 & 1669,5 & 3,0 & 0,701 & 60,3 & 0,4 & 0,78 \\
\hline \multicolumn{11}{|c|}{ Models applied on experimental set of data without mixes form groups O1 and O2 } \\
\hline EC2:2008 & 0,885 & 66,5 & 0,40 & 1,051 & 71,9 & 0,38 & 0,681 & 60,5 & 0,41 & 0,72 \\
\hline CEB MC90-99 & 0,835 & 63,5 & 0,45 & 0,980 & 70,8 & 0,44 & 0,631 & 55,1 & 0,47 & 0,61 \\
\hline MC2010 & 0,888 & 67,2 & 0,39 & 1,049 & 72,8 & 0,37 & 0,690 & 61,2 & 0,40 & 0,74 \\
\hline
\end{tabular}


In case models are applied on experimental data where mixtures from groups $\mathrm{O} 1$ and $\mathrm{O} 2$ (normal strength concrete) are excluded, the results for $F_{C E B}$ and $M_{C E B}$ are dramatically changed (Table 2) and they are in balance with results for period of 11 to 100 days. Statistical results for mixtures from groups $\mathrm{O} 1$ and $\mathrm{O} 2$ in first ten days of shrinkage are unrealistic because of dividing with very small values, near zero.

So, models prediction values for normal strength concrete in first ten days are significantly overestimated and all other results are underestimated $\left(F_{C E B}=63,5 \%\right.$ to $67,2 \%$ and $M_{C E B}=0,39$ to 0,45$)$ what is in conformance with graphical presentation in item 5.1.

\section{Influence of initial water curing on initial volume and mass change}

During description of the testing, it was indicated that specimens for testing influence of concrete cure in water were prepared in addition to specimens for the autogenous shrinkage testing. Test results of the change in length and mass at three days of concrete age for specimens cured for two days in water is shown in Fig. 8 for each mix.

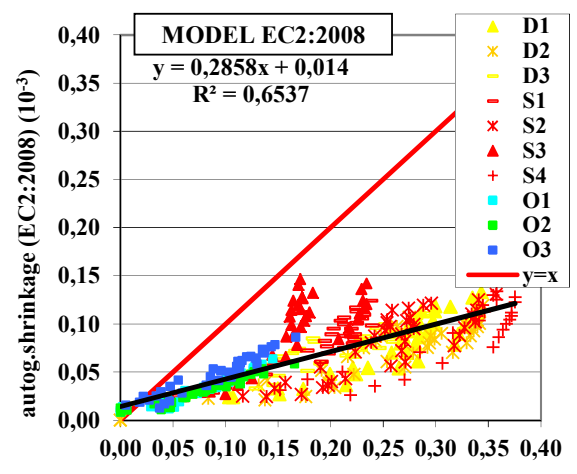

measured autog. shrinkage $\left(10^{-3}\right)$

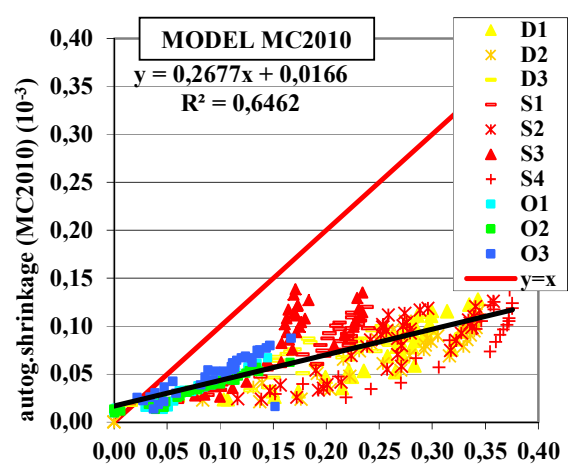

measured autog. shrinkage $\left(10^{-3}\right)$

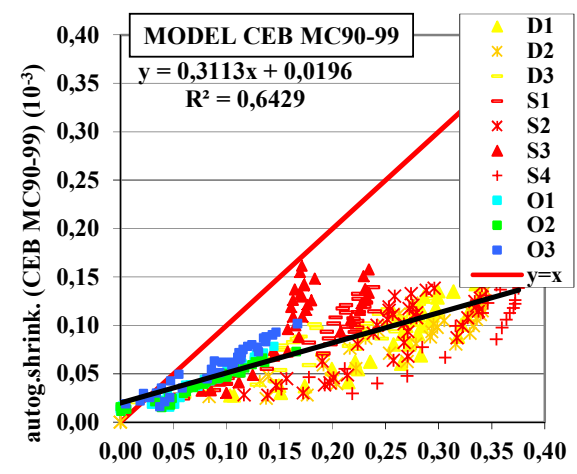

measured autog. shrinkage $\left(10^{-3}\right)$

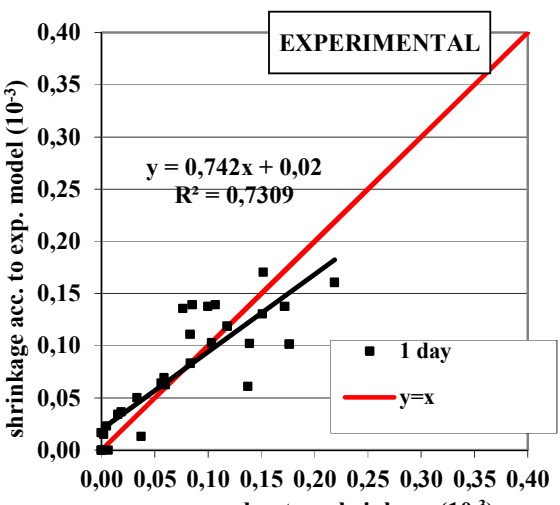

measured autog. shrinkage $\left(10^{-3}\right)$

Fig. 7 Correlation between experimental results and data obtained by theoretical models for prediction of autogenous shrinkage.

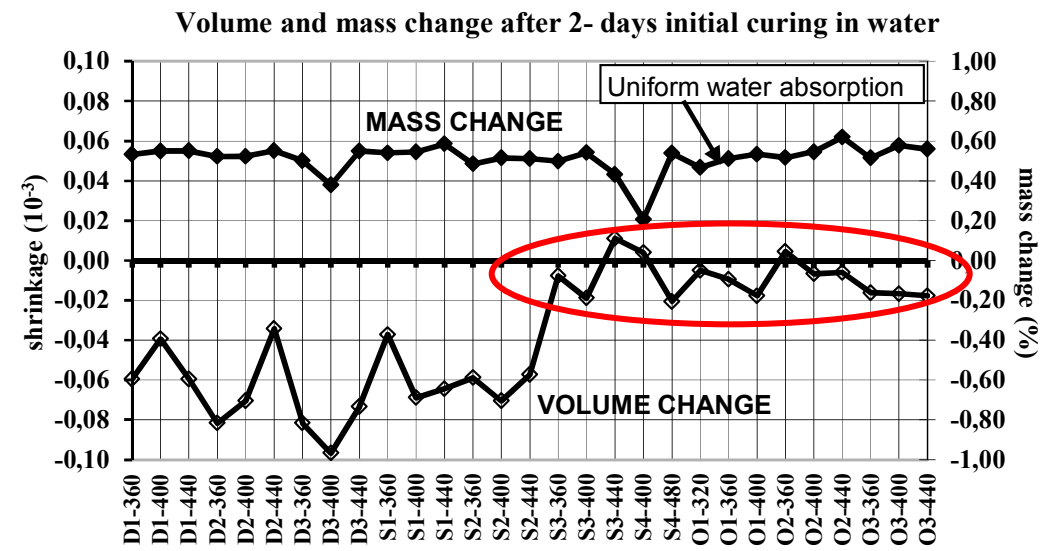

concrete mix mark

Fig. 8 Shrinkage (swelling) and mass change of concrete specimens after 2-days initial curing in water. 
It can be seen in Fig. 8 that one part of concrete specimens that were immersed in water for two days exhibits a very small change in volume, i.e. a negligible swelling (circled results). These are the groups with highest strength concrete, above $90 \mathrm{MPa}$ (groups S3 and S4) and groups with normal strength concrete up to about $60 \mathrm{MPa}$ (groups $\mathrm{O} 1, \mathrm{O} 2$ and $\mathrm{O} 3$ ).

The previously described change in volume is accompanied with the change in concrete mass. In general terms, the mass of specimens immersed in water increased uniformly from about 0,5 to 0,6 percent with few exceptions (Fig. 8). Therefore, regardless of differences in the change of volume, an increase in mass due to water absorption is quite uniform for specimens that were immersed in water for two days. The increase in the mass of high strength concrete groups D1, D2, D3, $\mathrm{S} 1$, and $\mathrm{S} 2$ is accompanied with swelling, as could have been expected. No significant swelling was registered for concrete groups $\mathrm{O} 1, \mathrm{O} 2$, and $\mathrm{O} 3$, but the change in mass was noted. The assumption is that the water penetrated into the already widened structure of concrete. The zero measurement was made on specimens taken from moulds, prior to immersion in water, i.e. at the time of maximum autogenous expansion of normal strength concrete. The absorbed water did not allow autogenous shrinkage that was observed on sealed specimens after initial expansion.

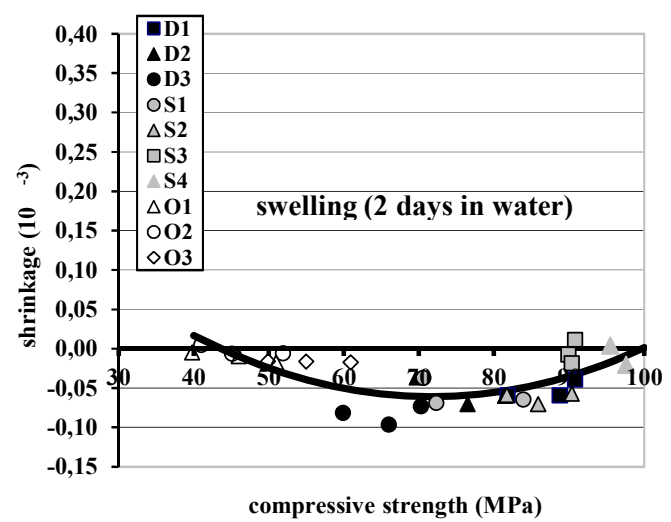

Fig. 9 Shrinkage of concrete cured in water for two days (negative shrinkage, swelling) and approximation curve.

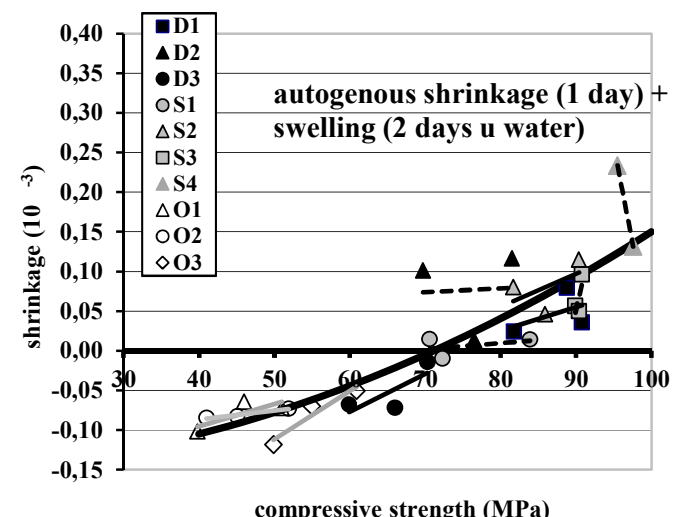

Fig. 10 Total deformation of concrete cured in water for two days and approximation curve.
This increase in mass without swelling was also registered for concrete groups S3 and S4. Previous autogenous expansion of concrete in group S3 could be the reason for this occurrence, but it was not registered for concrete in group S4. The common feature of these two concrete groups is that they have the greatest compressive strength values and small water binding ratios. It is possible that, due to accelerated hydration, the cement gel structure was so hard that it did not allow swelling to occur, or that the absorbed water was consumed for the accelerated hydration of cement (Zhutovsky and Kovler 2013).

Figure 9 shows results obtained by measuring the change in length of concrete specimens cured in water for two days, i.e. swelling of specimens as related to compressive strength of concrete, presented by group.

The following expression was used for the approximation of swelling in water:

$$
\varepsilon_{v}=0,000774 \cdot f_{c m 28}^{2}-0,0111 \cdot f_{c m 28}+0,3372
$$

$\varepsilon_{v}$ concrete swelling after the two-day cure in water $\left(10^{-3}\right.$ or $\left.\mathrm{mm} / \mathrm{m}\right)$

By adding the autogenous shrinkage of concrete at one day of age, and the change in length of concrete due to cure in water, we obtain the total deformation of concrete three days after production, as described with the parabola equation (Fig. 10):

$$
\varepsilon_{s h 3}=0,00003036 \cdot f_{c m 28}^{2}-0,1538
$$

The correlation coefficient amounts to 0,78 .

According to this model, the total shrinkage of concrete after two day cure in water, at three days of age, is greater than zero for concrete with the compressive strength of $68,8 \mathrm{MPa}$ or more. In case of concrete with the compressive strength lower than $68,8 \mathrm{MPa}$ the negative shrinkage or swelling is registered. It can be concluded that, by water curing, the compressive strength limit at which shrinkage is observed increases by 7,5 $\mathrm{MPa}$, if compared with the straight line shown in Fig. 5.

The autogenous shrinkage measured on sealed specimens in the period from the first to the third day after concrete preparation is either fully or partly compensated due to water curing of high strength concrete specimens (Figs. 9 and 10). It is not certain whether a prolonged cure would further influence reduction of autogenous shrinkage of concrete because of impermeable structure of high strength concrete that develops over time (Zhutovsky and Kovler 2013).

\section{Conclusions}

- Autogenous shrinkage results for one group of concrete mixtures made with the cement CEM II/A-S $42,5 \mathrm{R}$ that has the same quantity of water can be approximated in one time interval with a straight line. The area of all autogenous shrinking test results, with respect to compressive strength in one time interval, 
is a set of uniformly oriented lines until the strength value of $90 \mathrm{MPa}$.

- The autogenous shrinkage of the concrete group with the same quantity of water increases with an increase in compressive strength (i.e. with an increase in quantity of cement), but after the strength of about 70 $\mathrm{MPa}$, the shrinkage increase rate decreases.

- Large dispersion of autogenous shrinkage test results for concrete strengths of more than $70 \mathrm{MPa}$ was registered due to differences in concrete compositions for specific compressive strength.

- According to the engineering approach, the autogenous shrinkage of concrete, regarded at the age of one day, can be approximated with a parabola. The autogenous shrinkage value at the age of one day is important because it provides, when added to the shrinkage value measured in a conventional way, the total value of concrete shrinkage.

- The compressive strength of $60 \mathrm{MPa}$ is rightfully accepted as the limit strength for the normal strength and high strength concretes. A concrete with the strength of less than $60 \mathrm{MPa}$ exhibits a negative autogenous shrinkage or autogenous expansion after the start of the setting process which is the possible reason of low initial shrinkage of normal strength concrete.

- The autogenous shrinkage of normal strength concrete needs much more than one day to reach the initial autogenous expansion value.

- Out of possible autogenous expansion causes cited in literature, it was concluded that this expansion is not due to the addition of retarder or due to the increased quantity of bellite in cement, and that it is probably due to re-absorption of water at the start of the cement setting process. Normal strength concrete exhibits significant autogenous expansion due to greater quantity of water then in high strength concrete.

- The autogenous shrinkage defined in theoretical models EC2-2008, CEB MC90-99 and MC2010 is significantly underestimated with respect to experimental data for concrete made with CEM II/A-S $42,5 \mathrm{R}$ and overestimated for early age normal strength concrete.

- The concrete cured in water for two days absorbs water and has a uniform mass increase of about 0,5 to 0,6 percent and, at that, the normal strength concrete slightly swells, as the water probably penetrates the structure that has previously been widened by autogenous expansion. The same is true for concrete with the strength of more than $90 \mathrm{MPa}$ but for different reasons, probably because of consumption of water for accelerated hydration. The concrete with the strength ranging between 60 and $90 \mathrm{MPa}$ absorbs water and swells.

- The cure in water increases the strength at which there is no negative autogenous shrinkage by 7,5 $\mathrm{MPa}$.

\section{References}

ACI (American Concrete Institute), (2008). "Guide for modelling and calculating shrinkage and creep in hardened concrete." Farmington Hills, MI, USA : American Concrete Institute, ACI 209R-08.

Aïtcin, P. C., (1998). "Autogenous shrinkage measurement." In: E. Tazawa, Ed. Proceedings of the International Workshop on Autogenous shrinkage of Concrete, Hiroshima, 13-14 June 1998. London and New York: Taylor \& Francis, 257-268.

CEN, (2003). "EN 1991-1-5:2003: Eurocode 1: Actions on structures - Part 1-5: General actions - Thermal actions." Brussels, BE: CEN.

CEN, (2004+2008). "EN 1992-1-1:2004 + AC:2008: Eurocode 2: Design of concrete structures - Part 1-1: General rules and rules for buildings." Brussels, BE: CEN.

CEN, (2009). "EN 12350-2:2009: Testing fresh concrete - Part 2: Slump-test." Brussels, BE: CEN.

CEN, (2009). "EN 12350-5:2009: Testing fresh concrete - Part 5: Flow table test." Brussels, BE: CEN.

CEN, (2009+2011). "EN 12390-3:2009 + AC:2011: Testing hardened concrete - Part 3: Compressive strength of test specimens." Brussels, BE: CEN.

CEN, (2000+2004+2005). "EN 206-1:2000+A1: 2004+A2:2005: Concrete - Part 1: Specification, performance, production and conformity." Brussels, BE: CEN.

CEN, (2013). "EN 206:2013: Concrete: Specification, performance, production and conformity." Brussels, BE: CEN.

DIN, (2008). "DIN 1045-1:2008: Concrete, Reinforced Concrete and Prestressed Concrete Structures, Part 1: Design and Construction." Berlin, DE: DIN.

fib, (1999). "Structural concrete - Textbook on Behaviour, Design and Performance - Updated Knowledge of the CEB/FIP Model Code 1990." Lausanne, CH: FIB, Bulletin 2, V.2.

fib, (2010). "CEB-FIP Model Code 2010, First complete draft." Lausanne, CH: FIB.

Hammer, T. A., (1998). "Test methods for linear measurement of autogenous shrinkage before setting." In: E. Tazawa, Eds. Proceedings of the International Workshop on Autogenous shrinkage of Concrete, Hiroshima, 13-14 June 1998. London and New York: Taylor \& Francis, 143-154.

Hanehara, S., Hirao, H. and Uchicawa, H., (1998). "Relationships between autogenous shrinkage, and the microstructure and humidity changes at inner part of hardened cement paste at early age." In: E. Tazawa, Ed. Proceedings of the International Workshop on Autogenous shrinkage of Concrete, Hiroshima, 13-14 June 1998. London and New York: Taylor \& Francis, 93-104.

Holt, E. and Leivo, M. T., (1998). "Autogenous shrinkage at very early ages." In: E. Tazawa, Eds. Proceedings of the International Workshop on Autogenous shrinkage of Concrete, Hiroshima, 13-14 
June 1998. London and New York: Taylor \& Francis, 135-143.

Holt, E., (2001). "Early age autogenous shrinkage of concrete." Finland: VTT Technical Research Centre of Finland, VTT Publications.

Ishida, T., Chaube, R.P., Kishi, T. and Maekawa, K., (1998). "Microphysical approach to coupled autogenous and drying shrinkage of concrete." In: E. Tazawa, Eds. Proceedings of the International Workshop on Autogenous shrinkage of Concrete, Hiroshima, 13-14 June 1998. London and New York: Taylor \& Francis, 301-312.

JCI (Japan Concrete Institute) (1998) Technical Committee on Autogenous Shrinkage of Concrete: Committee Report. In: E. Tazawa, Eds. Proceedings of the International Workshop on Autogenous shrinkage of Concrete, Hiroshima, 13-14 June 1998. London and New York: Taylor \& Francis, 1-62.

JCI (Japan Concrete Institute) (1998) Technical committee on autogenous shrinkage of concrete: discussions and conclusions. In: E. Tazawa, Ed. Proceedings of the International Workshop on Autogenous shrinkage of Concrete, Hiroshima, 13-14 June 1998. London and New York: Taylor \& Francis, 385-405.

Jensen, O.M., Hansen, P.F., (2001). "Water-entrained cement-based materials, I. Principles and theoretical background." Cement and Concrete Research, 31, 647-654.

Mehta, P. K. and Monteiro, P. J. M., (2006). “Concrete, microstructure and properties of hardened concrete." 3rd ed., New York: McGraw-Hill.

Paulini, P., (1990). "Reaction mechanisms of concrete admixtures." Cement and Concrete Research, 20, 910-918.

RILEM TC 107-CSP, (1998). "Creep and shrinkage prediction models: Principles of their formulation Measurement of time-dependent strains of concrete." Materials and Structures, 31, 507-512.

Saje, D., (2001). "Compressive strength and shrinkage of high strength concrete." Thesis (PhD). University in Ljubljana, Faculty of civil and geodetic engineering.

Tazawa, E. and Miyazawa, S., (1995). "Influence of cement and admixture on autogenous shrinkage of cement paste." Cement and Concrete Research, 25 (2), 281-287.

Tazawa, E., Sato, R., Sakai, E. and Miyazawa, S., (2000). "Work on JCI Committee on autogenous shrinkage." In: V. Baroghel - Bouny and P. C. Aitcin, Eds. RILEM Proceedings PRO 17: Shrinkage of Concrete-Shrinkage 2000, 21-40.

Yang, Y., Sato, R. and Kawai, K., (2005). "Autogenous shrinkage of high strength concrete containing silica fume under drying at early ages." Cement and Concrete Research, 35, 449-456.

Zhutovsky, S. and Kovler, K., (2013). "Hydration kinetics of high-performance cementitious systems under different curing conditions." Materials and Structures, 46, 1599-1611. 